\title{
Pirated Software: The Relationship between Factors
}

\author{
Norizan Anwar (Corresponding author) \\ Faculty of Information Management, Universiti Teknologi MARA \\ Puncak Perdana Campus, Section U10, 40150 Shah Alam, Selangor, Malaysia \\ Tel: 60-19-234-5700Ｅ-mail: norizananwar@gmail.com
}

\begin{abstract}
Farrah Diana Saiful Bahry
Faculty of Information Management, Universiti Teknologi MARA

Puncak Perdana Campus, Section U10, 40150 Shah Alam, Selangor, Malaysia

Tel: 60-19-2084-038Ｅ-mail: farrahdiana@salam.uitm.edu.my
\end{abstract}

\begin{abstract}
Noraizan Amran
Faculty of Information Management, Universiti Teknologi MARA

Puncak Perdana Campus, Section U10, 40150 Shah Alam, Selangor, Malaysia
\end{abstract}

Tel: 60-12-340-0877Ｅ-mail: noraizan@salam.uitm.edu.my

Received: August 21, 2014 Accepted: November 17, $2014 \quad$ Published: February 1, 2015

doi:10.5296/jmr.v7i2.6945 URL: http://dx.doi.org/10.5296/jmr.v7i2.6945

\begin{abstract}
The advancement of Information Technology (IT) gadgets will indirectly encourage or influence users out there to use pirated software for any reason. Users may claim why they commit software piracy for varied reasons. Thus, this study aims to investigate the relationship of software piracy among information professionals in Klang Valley, Malaysia. The dependent variable is the Degree of Hardcore Pirate (DHP) while the independent variables include the Impression Management (IM), Personal Attributes (PA), Pirating Behavior (PB), Reciprocal Fairness (RF), Procedural Fairness (PF), Perceptions (P), Subjective Norms (SN), Intention (I) and Ethical Standards (ES). The finding of this study reveals that only two (2) out of nine (9) factors are significantly related to software piracy among information professionals in Klang Valley, Malaysia.
\end{abstract}




\section{Macrothink}

Journal of Management Research ISSN 1941-899X 2015, Vol. 7, No. 2

Keywords: Pirated Software, Degree of Hardcore Pirate, Impression Management, Personal Attributes, Pirating Behavior, Reciprocal Fairness, Procedural Fairness, Perceptions, Subjective Norms, Intention, Ethical Standards, Information Professionals 


\section{Introduction}

No computers, tablets or smartphones can operate without dedicated software. Thus, the software needs and dependency are high. In addition, (Liu \& Fang, 2003) in their study highlighted that due to the advanced development of information technology (IT), lifestyle and social structure of the individual have been revoked completely, which in return have causes strong dependence on IT. Thus, it is not surprising if the number of total lost by software vendors is increasing year-by year as reported by the Business Software Alliance (BSA).

In addition to that, in Johor, Malaysia, the Business Software Alliance (Business Software Alliance Website, 2013) reported that there are raids for software piracy in September 2013 where computers and suspected pirated software seized cost more than RM266, 000. During the raids, the branch head of Enforcement Officers from the Enforcement Division of the Ministry of Domestic Trade, Co-operatives and Consumerism (MDTCC) Muar Branch Office, mentioned that their ministry targeted to turn over a new leaf during the 'Ops Tulen Semak' (software piracy) campaign. Therefore, any organization in Malaysia must obey and follow the enforcement where the MDTCC is able and will take enforcement action against any organization that runs or operates in violation of the Copyright Act 1987, which stipulates that only licensed and legal software can be used in a business environment. The organization and its management are liable to be fined from RM2, 000 and up to RM20, 000 for each illegal copy of any software if caught violating the law. In addition, the organization's directors and/or senior management may also be imprisoned for up to five years.

Furthermore, in October 2013, a dialogue with the PC manufacturers and IT associations organized by the Ministry Enforcement Division was held where they discussed on how they can collectively help to reduce piracy risk and malware infections arising from illegal software activities which put consumers at risk (The Malaysian Times Website, 2013).

In relation to the above literature, this study attempts to measure the relationship between pirated software factors.

\section{Literature Review}

Quite a number of studies have been conducted on software piracy across several disciplines such the ethics, ethical behavior, use, and etc. (Glass \& Wood, 1996; Douglas, Cronan, \& Behel, 2007; Liu \& Fang, 2003; Siegfried, n.d.; Hinduja, 2003; Becker \& Ulstad, 2007; Namlu \& Odabasi, 2007; Haque, Rahman, \& Khatibi, 2010; Nill, Schibrowsky, \& Peltier, 2010; Suki, Ramayah, \& Suki, 2011 and Anwar, Bahry \& Amran, 2012). Due to the varied studies carried out, we can see various terms and definitions in regards to software piracy. Through these literatures, pirated software can be defined as the activity of installation and use of any type of software with unauthorized permission.

Furthermore, (Liu \& Fang, 2003) used the theory of reasoned action (TRA) as their theoretical intention model where they studied on the intention factors that affect the behavior. To support this study on ethical behavior, a study was conducted by (Becker \& Ulstad, 2007), where they measured if there are any significant effects on academic cheating between 
genders among students by adopting the Personal Attributes Questionnaire (PAQ) which is studied by (Spence et. al., 1975) previously. Moreover, (Siegfried, n.d.) found that the students' attitude on ethical use of computers, IT and software piracy has become a subject of great interest in the past decade. Quite a number of students have also committed software piracy in many ways in Universities (Hinduja, 2003). In a circumstance to reduce unethical and illegal behavior, as cited by (Hinduja, 2003), (Hinduja, 2002) they mentioned that there are techniques of neutralization that can be imposed by software pirates such as blaming the relatively high/expensive software prices which induces to their misappropriation, or faulting the greedy profiteering motives by software corporations.

From the literature review conducted above, the variables division used in this study is as follows:

Table . The Division of Variables Used

\begin{tabular}{ll}
\hline Variable & Author(s) \\
\hline Degree of Hardcore Pirate (DHP) & Hinduja, 2003 \\
Impression Management (IM) & Becker \& Ulstad, 2007 \\
Personal Attributes (PA) & Becker \& Ulstad, 2007 \\
Pirating Behavior (PB) & Hinduja, 2003 \\
Reciprocal Fairness (RF) & Douglas, Cronan, \& Behel, 2007; Suki, Ramayah, \& \\
& Suki, 2011; Anwar, Bahry \& Amran, 2012 \\
Procedural Fairness (PF) & Douglas, Cronan, \& Behel, 2007; Suki, Ramayah, \& \\
& Suki, 2011; Anwar, Bahry \& Amran, 2012 \\
Perceptions (P) & Siegfried, n.d. \\
Subjective Norms (SN) & Anwar, Bahry \& Amran, 2012 \\
Intention (I) & Liu \& Fang, 2003 \\
Ethical Standards (ES) & Hinduja, 2003 \\
\hline
\end{tabular}

In measuring the objective of study, we basically adopted and adapted the works of (Hinduja, 2003; Liu \& Fang, 2003; Becker \& Ulstad, 2007; Douglas, Cronan, \& Behel, 2007; Suki, Ramayah, \& Suki, 2011; Anwar, Bahry \& Amran, 2012 \& Siegfried, n.d). Hence, the dependent variable is the Degree of Hardcore Pirate (DHP). The independent variables include the Impression Management (IM), Personal Attributes (PA), Pirating Behavior (PB), Reciprocal Fairness (RF), Procedural Fairness (PF), Perceptions (P), Subjective Norms (SN), Intention (I) and Ethical Standards (ES).

\section{Research Framework}

Figure 1 depicts the framework for studying the relationship of pirated software and its factors. The framework is adopted and adapted based on the works of (Hinduja, 2003; Liu \& Fang, 2003; Becker \& Ulstad, 2007; Douglas, Cronan, \& Behel, 2007; Suki, Ramayah, \& Suki, 2011; Anwar, Bahry \& Amran, 2012 \& Siegfried, n.d). The factors measured in this study are the dependent variable, which is the Degree of Hardcore Pirate (DHP) whereas the independent variables are the Impression Management (IM), Personal Attributes (PA), 


\section{Macrothink}

Pirating Behavior (PB), Reciprocal Fairness (RF), Procedural Fairness (PF), Perceptions (P), Subjective Norms (SN), Intention (I) and Ethical Standards (ES).

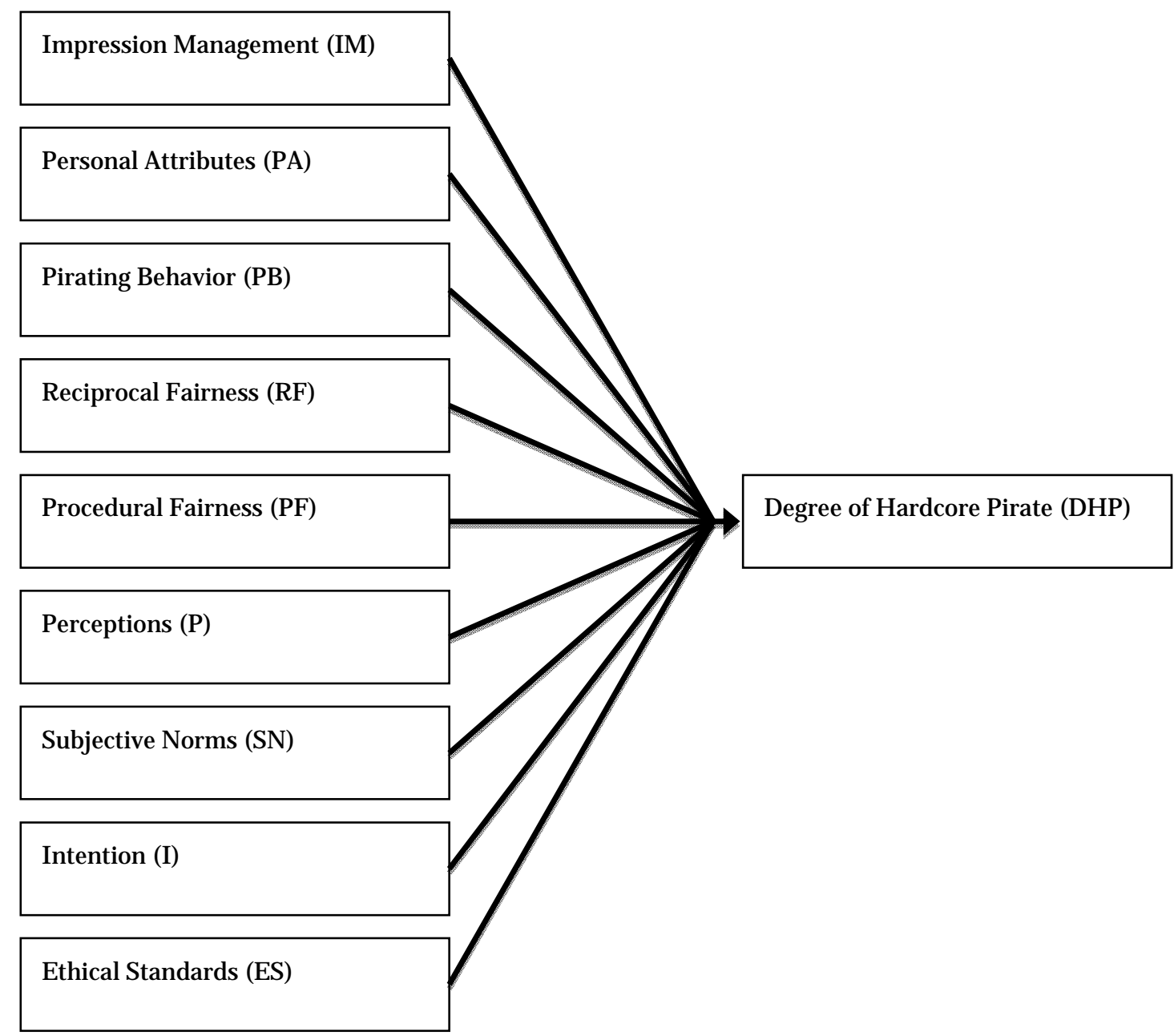

Figure . Research Framework

\section{Methodology}

\subsection{Instrument and Method}

The instrument used for collecting data is the questionnaire. The questionnaire is adapted and adopted from (Hinduja, 2003; Liu \& Fang, 2003; Becker \& Ulstad, 2007; Douglas, Cronan, \& Behel, 2007; Suki, Ramayah, \& Suki, 2011; Anwar, Bahry \& Amran, 2012 \& Siegfried, n.d). However, some modifications were made to suit and cater for the environment. The questionnaire is divided into 11 parts, where part A captures the information on demographic whereas parts $\mathrm{B}$ to $\mathrm{K}$ capture the information for measuring the independent and dependent variables. There are 8 questions in Part A, 20 questions in Part B, 16 questions in Part C, 8 questions each in Parts D and E, 2 questions each in Parts F and G, 30 questions in Part H, 3 questions each in Parts I and J and 7 questions in Part K. Thus, overall, there are 107 items all together used in the questionnaire. 
All measures for the variables are shown in Figure 1 which use several scale styles. Part B uses the Likert scale with seven extremes with 1 for "Not True" and 7 for "Very True", Part C uses the semantic differential scale, Parts D, F, G, H, I, J use the Likert scale with five extremes with 1 indicating "Strongly Disagree", 2 for "Disagree", 3 for "Undecided / Neutral", 4 for "Agree" and 5 for "Strongly Agree", Part E uses the combination of "Yes" and "No" and the number of frequency and Part K is similar to Part E which uses the Likert scale with five extremes with 1 for "Strongly Disagree", 2 for "Disagree", 3 for "Undecided / Neutral", 4 for "Agree" and 5 for "Strongly Agree" and "Yes" and "No".

\subsection{Population and Sampling}

This study was conducted among information professionals in Klang Valley, Malaysia which includes the Federal Territory of Kuala Lumpur and Shah Alam areas. Basically, they work in varied business functions. This study uses the simple random sampling technique where 400 questionnaires were distributed to these information professionals and only 384 questionnaires were returned. However, 190 questionnaires were found unusable after data cleaning and only 194 qualified for data analysis. The Statistical Package for the Social Sciences version 20 is employed to analyze data.

\section{Results and Discussion}

\subsection{Respondents Profiles}

Table 2 presents the respondent's demographic profile. Looking at the gender, 109 out of all respondents are male and 85 are female. The majority of respondents are of the age of between $20-30$ years old while the minority i.e. $3 \%$ is less than 20 years old. In terms of education, 29\% are diploma holders, 16\% each are SPM/MCE and STPM/ Matriculation holders, $14 \%$ are degree holders, $10 \%$ are SRP/PMR holders, $8 \%$ are specialized certificate holders and 3\% are Master holders. 
Table . Respondents Profiles

\begin{tabular}{llll}
\hline Characteristics & \multicolumn{1}{c}{ Items } & Frequency & Percentage \\
\hline \multirow{2}{*}{ Gender } & Female & 85 & $44 \%$ \\
& Male & 109 & $56 \%$ \\
\multirow{5}{*}{ Age (years) } & Less than 20 & 6 & $3 \%$ \\
& 31-40 & 107 & $55 \%$ \\
& More than 40 & 69 & $36 \%$ \\
& SRP/PMR & 12 & $6 \%$ \\
& SPM/MCE & 20 & $10 \%$ \\
& STPM/ Matriculation & 32 & $16 \%$ \\
& Specialization Certificate & 32 & $16 \%$ \\
& Diploma & 15 & $8 \%$ \\
& Degree & 57 & $29 \%$ \\
& Master & 27 & $14 \%$ \\
& PhD & 6 & $3 \%$ \\
& Others & 0 & $0 \%$ \\
\hline
\end{tabular}

\subsection{Reliability Analysis}

The Reliability analysis was performed to ensure the scale's internal or reliability consistency strength. As stated by (Nunnally, 1967), the recommended minimum value of Cronbach's Alpha of 0.50 or above is consistent. Table 3 indicates that all variables are above the recommended cut-off value which is 0.6 . Hence, it suggests that the scale used in the study is highly reliable (Nunna01ly, 1978).

Table . Reliability Analysis

\begin{tabular}{lll}
\hline Variables & No. of Items & Cronbach's Alpha \\
\hline Degree of Hardcore Pirate (DHP) & 8 & 0.923 \\
Impression Management (IM) & 20 & 0.861 \\
Personal Attributes (PA) & 16 & 0.861 \\
Pirating Behavior (PB) & 8 & 0.796 \\
Reciprocal Fairness (RF) & 2 & 0.803 \\
Procedural Fairness (PF) & 2 & 0.843 \\
Perceptions (P) & 30 & 0.905 \\
Subjective Norms (SN) & 3 & 0.609 \\
Intention (I) & 3 & 0.852 \\
Ethical Standards (ES) & 7 & 0.751 \\
\hline
\end{tabular}




\subsection{Correlation Analysis}

Tables 4 and 5 exhibit the details of correlation coefficients across all variables. Hence, accoding to (Bryman \& Crammer, 2001), it is provision when any study measure strengths of a relationship.

Table . Correlation Analysis

\section{Correlations}

\begin{tabular}{lllllllllll}
\hline Variables & DHP & IM & PA & PB & RF & PF & P & SN & I & ES \\
\hline DHP & 1.000 & & & & & & & & & \\
IM & 0.516 & 1.000 & & & & & & & & \\
PA & -0.021 & 0.240 & 1.000 & & & & & & & \\
PB & 0.299 & 0.189 & 0.003 & 1.000 & & & & & & \\
RF & 0.497 & 0.365 & -0.095 & 0.260 & 1.000 & & & & & \\
PF & 0.463 & 0.429 & -0.052 & 0.173 & 0.733 & 1.000 & & & & \\
P & 0.411 & 0.262 & 0.033 & 0.337 & 0.383 & 0.408 & 1.000 & & & \\
SN & 0.231 & 0.136 & 0.111 & 0.177 & 0.089 & 0.109 & 0.578 & 1.000 & & \\
I & 0.298 & 0.147 & -0.043 & 0.342 & 0.046 & 0.055 & 0.530 & 0.617 & 1.000 & \\
ES & 0.171 & 0.054 & -0.041 & -0.015 & 0.199 & 0.276 & 0.076 & -0.045 & -0.011 & 1.000 \\
\hline
\end{tabular}

Table : Correlation Analysis

\begin{tabular}{|c|c|c|c|c|}
\hline Independent Variable & & $\begin{array}{l}\text { Dependent } \\
\text { Variable }\end{array}$ & r value & Correlation Analysis \\
\hline $\begin{array}{l}\text { Impression } \\
\text { Management (IM) }\end{array}$ & & & 0.516 & $\begin{array}{l}\text { Positive Strong } \\
\text { Relationship }\end{array}$ \\
\hline Personal Attributes (PA) & & & -0.021 & $\begin{array}{l}\text { Negative Very Weak } \\
\text { Relationship }\end{array}$ \\
\hline Pirating Behavior (PB) & & & 0.299 & $\begin{array}{l}\text { Positive Weak } \\
\text { Relationship }\end{array}$ \\
\hline $\begin{array}{l}\text { Reciprocal Fairness } \\
\text { (RF) }\end{array}$ & $\rightarrow$ & $\begin{array}{l}\text { Degree of } \\
\text { Hardcore Pirate }\end{array}$ & 0.497 & \\
\hline $\begin{array}{l}\text { Procedural Fairness } \\
\text { (PF) }\end{array}$ & & & 0.463 & $\begin{array}{l}\text { Positive Moderate } \\
\text { Relationship }\end{array}$ \\
\hline Perceptions (P) & & & 0.411 & \\
\hline Subjective Norms (SN) & & & 0.231 & \\
\hline Intention (I) & & & 0.298 & $\begin{array}{l}\text { Positive Weak } \\
\text { Relationship }\end{array}$ \\
\hline Ethical Standards (ES) & & & 0.171 & \\
\hline
\end{tabular}

\subsection{Regression Analysis}

To this effect, the following equation is formulated i.e. Relationship Between Pirated Software and Degree of Hardcore Pirate $(\mathrm{DHP})=\beta 1 \mathrm{IM}+\beta 2 \mathrm{PA}+\beta 3 \mathrm{~PB}+\beta 4 \mathrm{RF}+\beta 5 \mathrm{PF}+$ 
$\beta 6 \mathrm{P}+\beta 7 \mathrm{SN}+\beta 8 \mathrm{I}+\beta 9 \mathrm{ES}+\xi$. Tables 6 and 7 exhibit the results of the multiple regression analysis. The $\mathrm{R}$ square value recorded 0.672 as shown in Table 6. Hence, it implies that $67.2 \%$ variance in the DHP can be explained by the combination of independent variables which include the Impression Management (IM), Personal Attributes (PA), Pirating Behavior (PB), Reciprocal Fairness (RF), Procedural Fairness (PF), Perceptions (P), Subjective Norms (SN), Intention (I) and Ethical Standards (ES).

Table . Model Summary of Regression Analysis Between Independent Variables and Dependent Variables

Model Summary

\begin{tabular}{lllll}
\hline Model & $\mathrm{R}$ & $\mathrm{R}$ Square & Adjusted R Square & Std. Error of the Estimate \\
\hline 1 & $0.672^{\mathrm{a}}$ & 0.451 & 0.424 & 0.96846 \\
\hline
\end{tabular}

a. Predictors: (Constant), IM, PA, PB, RF, PF, P, SN, I, ES

a. Dependent Variable: DHP

The results showed that out of nine (9) investigated independent variables, only two (2) turned out to be influential in predicting the DHP. These variables are the Personal Attributes $(\mathrm{t}=3.006, \mathrm{p}<0.05)$ and Reciprocal Fairness $(\mathrm{t}=2.828, \mathrm{p}<0.05)$. The other seven $(7)$ variables were found to be not significant as the recorded p-values were greater than 0.05 . Hence, based on the results, the equation is revised to DHP $=-0.135 \mathrm{PA}+0.253 \mathrm{RF}-0.938$.

Table . Coefficient Table for Variables Predicting ISRIS

Coefficients $^{a}$

\begin{tabular}{llllll}
\hline Model & \multicolumn{2}{l}{$\begin{array}{l}\text { Unstandardized } \\
\text { Coefficients }\end{array}$} & $\begin{array}{l}\text { Standardized } \\
\text { Coefficients }\end{array}$ & $\mathrm{t}$ & Sig. \\
& $\mathrm{B}$ & Std. Error & Beta & \\
\hline (Constant) & -0.938 & 0.501 & & -1.871 & 0.063 \\
IM & 0.409 & 0.073 & 0.361 & 5.573 & 0.000 \\
PA & -0.135 & 0.105 & -0.076 & -1.291 & 0.198 \\
PB & 0.110 & 0.087 & 0.077 & 1.263 & 0.208 \\
RF & 0.253 & 0.084 & 0.252 & 3.006 & 0.003 \\
PF & 0.033 & 0.080 & 0.036 & 0.415 & 0.678 \\
& 0.172 & 0.149 & 0.092 & 1.157 & 0.249 \\
P & 0.011 & 0.087 & 0.010 & 0.129 & 0.898 \\
SN & 0.133 & 0.070 & 0.147 & 1.904 & 0.058 \\
I & 0.142 & 0.095 & 0.085 & 1.482 & 0.140 \\
ES & & & &
\end{tabular}

a. Dependent Variable: DHP

\section{Results and Discussion}

To achieve the objective, an empirical study based on the adopted framework consisting nine 
(9) independent variables which include the Impression Management (IM), Personal Attributes (PA), Pirating Behavior (PB), Reciprocal Fairness (RF), Procedural Fairness (PF), Perceptions (P), Subjective Norms (SN), Intention (I) and Ethical Standards (ES); and one dependent variable i.e. Degree of Hardcore Pirate (DHP) was developed. Referring to the analyses conducted on collected data, two (2) of the independent variables were found to be relevant in determining the DHP. Thus, this study has proven two (2) factors that influence the DHP among information professionals.

Based on the analysis and findings above, in future, the developed research model framework can be extended and tested. Besides that, researchers or practitioners can further explore the topic in other settings as well. Furthermore, this study also exists with a limitation in which the scope of sample may also cover across all areas instead of the dedicated areas in Klang Valley.

\section{Acknowledgement}

We would like to thank the Research Management Institute (RMI) with project code: 600-RMI/DANA 5/3/RIF (707/2012), Universiti Teknologi MARA (UiTM) for providing us with financial assistance. Besides that, our thanks are also dedicated to all respondents in the Federal Territory of Kuala Lumpur and Shah Alam areas. Not to forget, Wan Noor Sazidah Wan Fauzi, Iylia Liyana Ismail and Nor'afiza Ghazali for data collection and entry collaboration.

\section{References}

Liu, L-P., \& Fang, W-C. (2003). Ethical Decision-Making, Religious Beliefs and Software Piracy. Asia Pacific Management Review, 8(2), 185-200.

Ministry to curb software piracy. (2013). The Malaysia Times. Retrieved from The Malaysia Times Website: http://www.themalaysiantimes.com.my/ministry-to-curb-software-piracy/ on 7 February 2014.

Glass, R., \& Wood, W. (1996). Situational Determinants of Software Piracy: An Equity Theory Perspective. Journal of Business Ethics, 15(11), 89-98. http://dx.doi.org/10.1007/BF00412817

Douglas, D. E., Cronan, T. P., \& Behel, J. D. (2007). Equity perceptions as a deterrent to software piracy behavior. Information \& Management, 44, 503-512. http://dx.doi.org/10.1016/j.im.2007.05.002

Siegfried, R. M. (n.d.). Student Attitudes on Software Piracy and Related Issues of Computer Ethics. Retrieved from http://home.adelphi.edu/ siegfried/ETIN2004.pdf on 13 March 2013.

Hinduja, S. (2003). Trends and patterns among online software pirates. Ethics and Information Technology, 5, 49-61. http://dx.doi.org/10.1023/A:1024910523384

Becker, D. A., \& Ulstad, I. (2007). Gender Differences in Student Ethics: Are Females Really More Ethical? Plagiary: Cross Disciplinary Studies in Plagiarism, Fabrication, and Falsification, 77-91. 


\section{Macrothink}

Journal of Management Research

ISSN 1941-899X

2015, Vol. 7, No. 2

Namlu, A. G. \& Odabasi, H. F. (2007). Unethical computer using behavior scale: A study of reliability and validity on Turkish university students. Computers \& Education, 48, 205-215. http://dx.doi.org/10.1016/j.compedu.2004.12.006

Haque, A., Rahman, S. \& Khatibi, A. (2010). Factors Influencing Consumer Ethical Decision Making of Purchasing Pirated Software: Stuctural Wquation Modeling on Malaysian Consumer. Journal of International Business Ethics, 3(1), 30-40.

Nill, A., Schibrowsky, J., \& Peltier, J. W. (2010). Factors That Influence Software Piracy: A View from Germany. Communication of the ACM, 53(6), 131-134. http://dx.doi.org/10.1145/1743546.1743581

Suki, N. M., Ramayah, T., \& Suki, N. M. (2011). Understanding Consumer Intention with Respect to Purchase and Use of Pirated Software. Information Management \& Computer Security, 19(3), 195-209. http://dx.doi.org/10.1108/09685221111153564

Anwar, N., Bahry, F. D. S. \& Amran, N. (2012). Installation and Use of Pirated Software: The Factors Behind It. Proceeding of Business, Engineering and Industrial Applications (ISBEIA), $207-212$.

Nunnally, J. C. (1967). Psycometric Theory. McGraw- Hill, New York.

Nunnally, J. C. (1978). Psychometric Theory, McGraw-Hill, New York.

Bryman, A., and Crammer, D. (2001). Quantitative data analysis with SPSS release 10 for Windows (also suitable for SPSS release 11): a guide for social scientist. New York: Routledge.

Business Software Alliance. (2012, May). 2011 BSA Global Software Piracy Study: Ninth Edition. Retrieved from Business Software Alliance: http://globalstudy.bsa.org/2011/downloads/study_pdf/2011_BSA_Piracy_Study-Standard.pdf on 7 February 2014.

\section{Copyright Disclaimer}

Copyright for this article is retained by the author(s), with first publication rights granted to the journal.

This is an open-access article distributed under the terms and conditions of the Creative Commons Attribution license (http://creativecommons.org/licenses/by/3.0/). 